\title{
The university, creativity, and freedom
}

Gerald D. Buckberg, MD

From the David Geffen School of Medicine at the University of California at Los Angeles, Los Angeles, Calif.

Received for publication Feb 11, 2008; accepted for publication March 7, 2008.

Address for reprints: Gerald D. Buckberg, MD, David Geffen School of Medicine at UCLA, 10833 Le Conte Avenue, 62-258 CHS, Los Angeles, CA 90095 (E-mail: gbuckberg@mednet.ucla.edu).

J Thorac Cardiovasc Surg 2008;135:979-83 0022-5223/\$34.00

Copyright (C) 2008 by The American Association for Thoracic Surgery

doi:10.1016/j.jtcvs.2008.03.011
$\mathrm{T}$ The highest honor is to be recognized by your colleagues because you have helped them. I am humbled and grateful to share this acknowledgment of the Scientific Achievement Award of the American Association for Thoracic Surgery with Drs Kirklin, DeBakey, Cooley, Shumway, and Carpentier, who are my cardiac surgery heroes because their contributions have stimulated our learning. This award made me focus on factors that led to my work: the university, creativity, and freedom.

There are no boundaries, because interest in our field is shared by students, residents, academic surgeons, and nonacademic practitioners of cardiac surgery. The university is our similar starting position and where we are initially exposed to the value of creativity. I define creativity as "filling an empty room with new ideas, testing them, with ongoing change during the learning process." This avenue provides the freedom to select lifelong goals that are independent of our academic or nonacademic status. Simultaneously, we also learn that creativity confronts tradition.

Let me share 4 concepts. First, I learned to clarify the foundations for academic growth from the work of Claude Bernard, originally published in $1865 .{ }^{1}$ His book An Introduction to the Study of Experimental Medicine is a welcome addition to any library. He defines "the observers" who watch, "the experimenters" who change, and our need to return to become observers to help us to understand what we have done. Second, the role of the university is critical in such growth, because it is here we learn to begin. Third and fourth, the responsibility of our teachers is to guide us toward knowledge and to share a special theme that generates similarity between closely intertwined factors that might seem distant.

The practicing cardiac surgeon is the primary recipient of our experimental and clinical investigation. Collectively, we confront clinical dilemmas that must stimulate research pathways. Our fields of study are the operating room and intensive care unit. Initially, an experimental laboratory is used to simulate these conditions, and our findings are applied to patients. The results are reported, and new information is weighed by our peers and published in journals; sometimes these reviewers become judges or censors, and their bias can be obstructive. An opposing force is the practicing cardiac surgeon who always wants to improve and appreciates learning creative ways to change clinical barriers; the patient is the end point of our creative approaches.

Our voyage includes several components. Cardiac surgeons are blessed, because we exist in a world where passion for our work is overwhelming and steeply increases through learning. That ongoing pursuit requires special support, and Larry Cohn defined this several years ago during his American Association for Thoracic Surgery address on Academic Leadership, ${ }^{2}$ by relating this infrastructure to the powers and strength of the family. Our parents teach us to be honest, respective, and helpful to others. For me, my wife, Ingeborg, and my daughters, Nicole and Gia, played an integral role. Each knew of my love for research and cardiac surgery. They grew to understand that this drive did not sometimes allow a sharing of time expenditure, 
because pursuit of knowledge and solving problems often interfered with expected obligations, leading them to understand we are driven, almost blindly, by this world. My "family" has also expanded to include dedicated research fellows and residents who train with me and give me a chance to participate in their growth.

The guiding light of the Claude Bernard volume of 1865 demonstrated that the processes of thinking and learning are similar today as we enter the modern experimenter/observer world. The experimenter changes nature by introducing a bias or experimental environment and then must look at the result, now assuming the role of observer. We succeed by looking at nature and must appreciate that progress is often limited by the fears of those who retain a fixed position.

The university exposes all to the world where intellectual creativity flourishes and provides the academic gift of openmindedness. This infrastructure to grow and retain such learning persists in many who leave academic life. Conversely, some who stay may sometimes suffer the inescapable consequence of early academic success; they persist in the university but resist subsequent changes that stimulate future growth. They may gain leadership positions but may obstruct developments of new knowledge because they fear new change will impair their stature. In contrast, others with an open mind retain the intellectual spirit despite being outside the ivy walls of the university.

This perennial dilemma was described clearly by Galen, 1800 years ago. He was dismayed by Erasistratus, who was initially creative in 300 в.с. by describing cardiac function but did not subsequently grow. Troubled by this lack of continued growth, Galen then compared him with a truly unconscionable spirit, Lycus of Macedonia. However, Galen overcame his dislike by stating that we must remain attentive and search for the creative part of their knowledge, an attitude that conveys the centerpiece of academic freedom. Failure to continue creative action does not mean that special qualities of others should not be understood and fruitfully used in the future.

The ivy walls of the university contain students and professors who question and deliver new knowledge for our use. The "dream" is that students learn while growing, whereas professors grow while learning. The "reality" is that students are often wrong but always in doubt, whereas professors are sometimes wrong but never in doubt. There should be no fear to develop procedures to contradict current procedures, to accept the role to test innovative changes, to provide new seeds for progress. In the academic community, this attitude may be summarized as "the ignorant is unknowledgeable, but can learn, while the arrogant is knowledgeable, but cannot be taught."

We undergo "commencement" at university graduation to inaugurate our future. A similar new world for freedom of enactment also exists within our specialty. It never stops: bright, thoughtful, responsible participants who search only for ways to improve. They do not defend a position, whether academic or nonacademic because of concern that current leadership will be challenged. We understand the limitations of some in power who resist a changing future. The classic dichotomy is "power rules, but leadership guides."

The university is the springboard for the passionate drive toward creativity. It provides the solid infrastructure of knowledge and honesty. It gives endless seeds and fuel to continue to learn, evaluate, and use new information, independently of academic rank. My theme is to blend these comparable 2 fields: the university and the subsequent private community. This combination provides ways that creativity and intellectual freedom are transposed to new information for patient care.

A recently developed international surgical/cardiologic RESTORE team to treat heart failure defines this collaboration. There were 9 original surgical members. The entry criteria included that each participant retain the open mind that became defined during the early guidance of an academic position. Only 3 of 9 remained within the university; the others were in private practice, but all retained these intellectual seeds of wanting to change barriers to gauge and evaluate new information, act on it, and be unconcerned to do so despite departure from current methods. These faculties are the basic element of "experimental science," a resounding difference from "scholastics or systematizers" who retain fixed boundaries and cannot develop innovative change. This attitude seeds the obstructionists, who may unduly support a bias against creative and useful development, an action linked to their blindly upholding tradition.

No difference in attitudes existed among the RESTORE members who could identify their academic or nonacademic position. Each recognized that our limitation may be linked to what is known. We drive toward innovative discovery and that undergoes subsequent testing to create paradigm shifts that characterize growth. Our defense of what is known is not intrepid; the inquisitive spirit persists, and the fear to only protect currently acceptable positions is absent.

These "experimenters" are not afraid to create a bias or develop new tests to assess the viability of different options. They are different from "observers," who organize rather than evaluate. Clearly, the ivy walls are not a barrier, because this quest remains in those who escape academic life but retain pride in their freedom. Restraints are not based on fear of losing political or scientific positions. Those who retain this resistance remain as observers, who may be overrun by new knowledge; this is the irrepressible standard of progress.

Values of creative individuals develop because they band together in this quest. The leaders elect colleagues who are less recognized by current rank in their efforts to help make future leaders. The understood presumption is that each leader is so prominent that he or she cannot become more recognized. An unrecognized criterion is the willingness to share responsibility and guide junior colleagues toward new 
information. Acquiring knowledge for reporting is not only to create individual gain but also to contribute by involvement.

New information, through combined development, is then transmitted to the well-trained intellectual community of surgical practitioners. They also welcome a chance to understand and participate if sufficient proof of new knowledge exists. This is a unique collaboration between the development of change and those who evaluate and come to alter and refine this change. The foundations of scientific development and growth are through the action of these well-timed inquisitors.

This approach conforms to the Claude Bernard concept that "great men provide shoulders, upon which pygmies can stand and look further than they." This never diminishes their leadership; rather, it is essential for those who use them for support. To me, this attitude suggests that clarity reflects looking to learn while "standing upon the shoulders of established giants." This differs from the limited approach of "looking to become established giants" that is bestowed by others.

Historically, recognized contributors to the American Association for Thoracic Surgery have selected 4 leaders, so-called giants to them, who help shape their careers and give them a solid foundation for growth. We never start alone, nor do we win a lottery for success. Rather, we evolve from our own internal spirit and rely on the guidance of previous leaders.

A specific number 4 imposes a restriction, and that choice is useful. The primary attribute of a cardiac surgeon is to be a complete physician encompassing the knowledge, teaching, precision and organization, and complete attitude toward patient care. Dr William Longmire of the University of California in Los Angeles provided these characteristics to me during and after my surgical residency (Figure 1, upper left). The knowledge he would return from a trip at 2:00 A.M., go immediately to the hospital, rather than home, solidified his passion for dealing with sick people, rather than just the technical procedures he did so wonderfully. Our surgical approach became enmeshed with this drive, to operate, know, and grow. My most uncomfortable moment was one morning at 5:00 A.M., when a resident called me to tell of a brief convulsion of one of Dr Longmire's patients. The cause was low calcium, and this was cured by calcium restoration. I did not call the professor, knowing we would meet together at 7:00 A.M. for an operation. Only one thing was said as we were at the scrub sink. "How would you feel if you came to see a patient and the family asked you if her Mom would convulse again, and you didn't know what happened earlier"? A10-hour liver resection, under the technical mastery of this surgical genius, without a word said to me taught me a profound lesson about the completeness of surgical care. Clearly, the conceptual perfection and surgical mentorship of my chief was coupled with a caring attitude about the patient, the family, and our role in this grand scheme.

This desire to encourage new, untapped knowledge and provide total fidelity to those who come to learn with him characterized Julius Comroe (Figure 1, upper right). He was the head of the Cardiovascular Research Institute at the University of California in San Francisco. It is here that I learned the approach to research. An outstanding scholar and teacher, Dr Comroe fundamentally gave up his career in pulmonary research to create an institute that honed the seeds of educating future leaders. He was adamant to infuse us with the fundamentals of knowledge, to make us grow. The research fellow always had complete access to his attention, devotion, and unimpeded efforts to help us begin our lives. Conversely, a recognized international scientist coming to San Francisco could not see Dr Comroe without a prior appointment.

I will never forget his class of teaching us how to review the medical literature. He asked me to comment on an article in 1935, about blood pressure responses and the carotid artery; only 2 vessels were studied. (He loved to be with surgeons, because he knew that our ongoing drives would give physiologists years of study to solve our mistakes.) $\mathrm{He}$ demanded my editorial decision on this article that had limited data input, unclear tracings, unsupported concepts, and a brief 2-page report. We were given 45 minutes to read this 2-page article. Of course, I rejected this article because of low numbers, no statistics, poor tracings, and imprecise questioning of what is known. He gracefully accepted my surgical point of view but told me that my decision was unshared by the Nobel Committee, who gave the prize for this description of the carotid sinus reflex to Heyman and Heyman. A good surgical lesson for me: Listen, learn, but do not judge.

My guide at the Cardiovascular Research Institute was Dr Julien I. E. Hoffman, a cardiologist, physiologist, and thoughtful mentor (Figure 1, lower left). He showed me how to search and act responsibly with my data. A methodologist in his research, Dr Hoffman demanded certainty about our findings before any report. He taught us how to ask a question and how to search for an answer. He welcomed different views and evaluated each idea precisely. Then he sometimes told you, with incisive Rhodesian wit, that this may not be true. Tell him the water was purple, and he looked at it, inquired about the sun, the color of your glasses, and only after examining these factors would he either reject you on a solid basis or, more important, encourage your next step. He welcomed your ability to ask questions he had not thought of, rather than supply or provide a solution to what he already knew was true. The methods were critical to observation; a new thought was weighed only on its merit, if the matter of study was careful. Our data on small microspheres to measure regional flow within small regions of cardiac muscle followed this course. We were correct in this pursuit, but he nearly drove me and 4 other surgical residents crazy to be sure until this information was the true infrastructure of new knowledge. These flow measurements with microspheres, like red blood cells that became stuck and did 

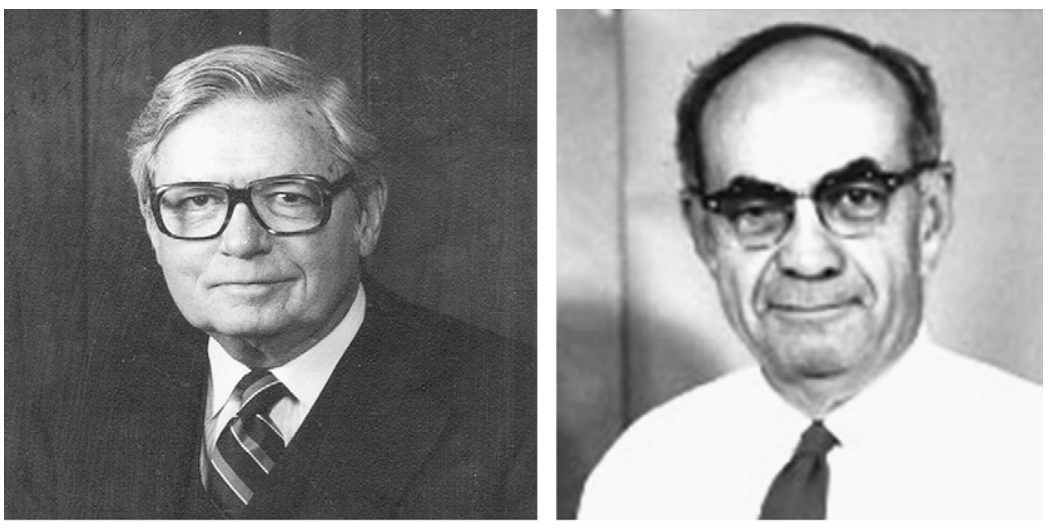

Figure 1. William Longmire (upper left), Julius Comroe (upper right), Julien I. E. Hoffman (lower left), and James Maloney (lower right).
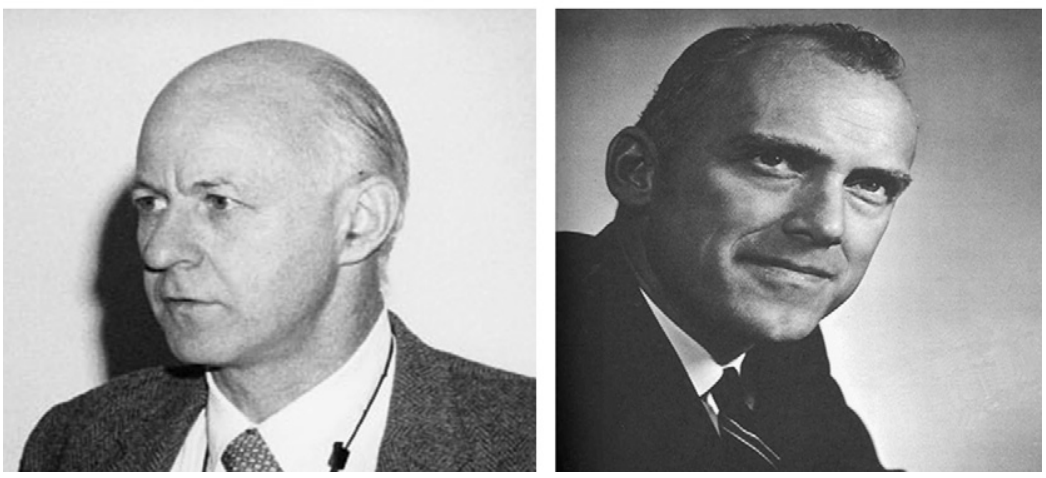

not pass through the circulation, are now routine for worldwide measurement of regional circulation in both the heart and all other organs. The article describing this work ${ }^{3}$ is the most quoted one of my career.

The capacity to practice surgery with a scientific infrastructure are the seeds of academic growth. As defined by Dr Comroe, you must use these traits, learned with devotion, to your future life. To do this, there must be an environment where such growth is possible. The existing leaders cannot be afraid of your ascent to your own position or concerned that their position of power will be diminished, or that your underling status will allow new knowledge to be theirs for taking. My fortune was to come to the University of California in Los Angeles and work with Jim Maloney (Figure 1, lower right).

I remember vividly the details of my first day after returning from the Cardiovascular Research Institute. I asked Jim about how many abstracts, articles, and reviews I needed to write. I stated that I was taught how to study, but not what to study, and where to report, not how to report, and to never think about how frequently to report. I only knew how to proceed, not where it would take me. I made it clear that if there were such requirements for production, presentation, I would need to look for another position immediately; I could not exist under such conditions. Jim looked at me, escorted me to his laboratory, and said, "Why don't you do what you want for the next 2 years. I will provide the people, the equipment, and tell you my thoughts as you show me the informa- tion you're developing. If, in 2 years, we need to have this conversation, we'll have it then." Of course, this never happened, and the subsequent development of blood cardioplegia, amino acid supplementation, reperfusion injury, reoxygenation injury, treating myocardial infarction, treating cardiogenic shock, coronary sinus cannulation, ventricular muscle restoration, and cardiac form and function followed these guidelines. To each of these mentors, I thank them for helping me, being resolute in evaluation and criticism, and providing the guidance needed as we begin the course of our development.

We will now turn to the effect of unperceived but similar factors that may seem so distant. My best example of a composite approach is drawn from a dear friend, Paco TorrentGuasp, who recently passed away. He defined a novel approach to providing macroscopic reasons for cardiac structure and function. He told me "Gerald, nature is simple. It is scientists who are complicated." He was able to solve the Gordian knot of anatomy imposed by Vesalius, Haller, and others. He showed that the heart was composed of 2 simple loops with a simple muscular internal band making a helix ${ }^{4}$ (Figure 2). The basal loop provided support, and the apical loop provided function for ejection and suction. In a sense, the apical loop is the motor for activity and surrounded by a buttress.

He organized this knowledge, which was initiated 2300 years ago by Erasistratus and then Galen, who contributed 


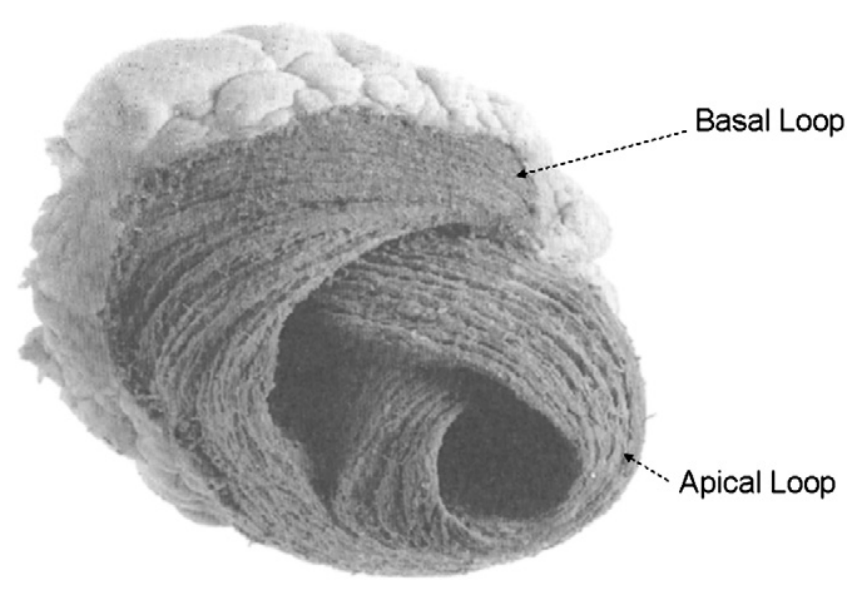

Figure 2. Spatial muscle configuration of the heart that is surrounded by a circumferential wrap of transverse fibers that encompass an oblique helical configuration with an apical vortex.

to the foundations of knowledge about heart physiology. Their time-honored concepts were maintained until the 17th century, when this was changed by William Harvey as he introduced circulatory physiology. Harvey was excellent, but he was not perfect. When he introduced the novel concept of the circulation, he disregarded, simultaneously, the knowledge of ancient scholars about how the heart fills by suction. This basic information has now been shown to be correct, because it is the infrastructure to normal cardiac form and function. The heart ejects and sucks by using a reciprocally twisting motion with angular momentum. Cardiac twisting and untwisting motions for ejection and suction are directed toward the apex of the helical heart that is its functional keystone.

A Gothic dome pattern exists in the heart, with a central apical loop and vortex for angular momentum that is surrounded by a basal loop for support. This was shown clearly by Paco Torrent-Guasp, who also found that similar cardiac structures existed in fish, amphibians, and lower life mammals before humans. Architecture and heart formation follow similar spatial themes. These guidelines imply that the gothic dome or prominence is surrounded by a powerful outer shell that is needed to avoid its destruction. Such joining involves different organizational planes to support function, and this configuration has humanistic implications.

I have been fortunate to be surrounded by special students, research associates, who are now colleagues. This liaison has made me grateful to have contributed something toward their future. I respect their accomplishments and know that they will become guides to others and keep this process growing.

The university, with its teachers and historic freedom, provides this infrastructure for creativity, and creates open minds to allow internal development of avenues from which growth can occur. That value creates persistence and desires for ongoing learning, components that are measurable in many surgical colleagues who practice inside and outside the ivycovered academic walls. It is these qualities that make me proud to be your recipient of the Scientific Achievement Award. I am grateful that my contributions have been useful and that evolution of this knowledge has promoted a positive view toward our future progress.

\section{References}

1. Bernard C. An Introduction to the Study of Experimental Medicine. New York: Dover Publications; 1957.

2. Cohn LH. Becoming a surgical leader. J Thorac Cardiovasc Surg. 2000; 119(4 Pt 2):S42-4.

3. Buckberg GD, Luck JC, Payne DB, Hoffman JIE, Archie JP, Fixler DE. Some sources of error in measuring regional blood flow with radioactive microspheres. J Appl Physiol. 1971;31:598-615.

4. Torrent-Guasp F, Ballester M, Buckberg GD, Carreras F, Flotats A, Carrio I, et al. Spatial orientation of the ventricular muscle band: physiologic contribution and surgical implications. J Thorac Cardiovasc Surg. 2001;122:389-92. 